\title{
REMOÇÃO DE CORANTE AZUL DE METILENO EM ÁGUAS RESIDUÁRIAS ATRAVÉS DE ADSORVENTES DE RESÍDUOS INDUSTRIAIS
}

\author{
G. C. ANDRETTA ${ }^{1}$, H. C. PAULETTI ${ }^{1}$, T. R. MORÁS ${ }^{1}$, G. L. COLPANI ${ }^{1}$. \\ ${ }^{1}$ Universidade Comunitária da Região de Chapecó/Unochapecó- ACEA - Engenharia \\ Química - Campos Chapecó - SC \\ E-mail para contato: hellen.cristina525@hotmail.com
}

\begin{abstract}
RESUMO - A utilização de materiais adsorventes economicamente viáveis tem despertado crescente interesse como técnica para remoção de contaminantes em águas. Desta forma, avaliou-se a adsorção do corante azul de metileno por carvões ativados quimicamente, oriundos de casca de laranja e lodo ativado. As condições analisadas para foram: ativação de 1 hora seguida de carbonização a 400 e $600{ }^{\circ} \mathrm{C}$, utilizando-se a razão mássica $\mathrm{H}_{3} \mathrm{PO}_{4}: \mathrm{H}_{2} \mathrm{O}$ igual 1:1. O modelo cinético de pseudossegunda ordem foi o que melhor se adequou aos dados experimentais, onde o carvão obtido da casca de laranja apresentou a constante $\mathrm{k}_{2}=0,001 \mathrm{~g} \cdot \mathrm{mg}^{-1} \cdot \mathrm{min}^{-1} \mathrm{e}$ o de lodo ativado $\mathrm{k}_{2}=0,052 \mathrm{~g} \cdot \mathrm{mg}^{-1} \cdot \mathrm{min}^{-}$ , ocorrendo uma redução de 98 e $77 \%$ do corante, respectivamente. A isoterma de Freundlich apresentou melhor ajuste aos dados, com uma constante $\mathrm{K}_{\mathrm{F}}=92,37\left(\left(\mathrm{mg} \cdot \mathrm{g}^{-}\right.\right.$ $\left.\left.{ }^{1}\right) .\left(\mathrm{L} \cdot \mathrm{mg}^{-1}\right)^{1 / \mathrm{n}}\right)$ e 24,68 ((mg.g $\left.\left.{ }^{-1}\right) \cdot\left(\mathrm{L} \cdot \mathrm{mg}^{-1}\right)^{1 / \mathrm{n}}\right)$, para a casca de laranja e lodo, respectivamente. Portanto, estes carvões podem ser efetivos na remoção corantes catiônicos.
\end{abstract}

\section{INTRODUÇÃO}

Com o crescente número de indústrias, observa-se um aumento significativo de efluentes gerados por estes processos, sendo necessário o tratamento adequado destes, antes de seu retorno ao meio ambiente, visando impedir contaminações.

Os corantes são resíduos de indústrias de papel, têxteis, plástico e gráficas, e a presença destes compostos em águas de abastecimento e efluentes é prejudicial à biota aquática devido seus produtos de degradação estarem relacionados à toxicidade e mutação desta biota, além de possuírem propriedades recalcitrantes e serem visualmente indesejáveis nos corpos d'água (Yanan et al., 2011; Mezohegyi et al., 2012;). Com o intuito de remover de forma eficiente os corantes, buscando evitar impactos ambientais, pesquisas têm sido focadas no desenvolvimento de novos processos que removam tais contaminantes dos sistemas hídricos (Wang, 2012).

A adsorção em carvão ativado é apontada como uma opção de remoção de contaminantes para esse tratamento, porém a efetividade do carvão é variada, dependendo de matéria-prima, modo de ativação, sua afinidade com a água comparada à sua afinidade pelo adsorvente, o pH e composto a ser adsorvido, conferindo características diferenciadas e resultando em diferentes capacidades de adsorção. Devido às perdas durante o processo, existe o interesse na busca por materiais de baixo custo que possam ser utilizados na produção de carvão ativado. No geral pode ser produzido a partir de materiais como, casca de coco, sementes, ossos, entre outros (Silva, 2005). 
Como alternativa aos materiais comumente empregados para a produção de carvão ativado, sugere-se a casca de laranja, pois segundo o IBGE (2012), somente o estado de Santa Catarina produziu, em 2011, aproximadamente 81 toneladas de laranja. No entanto, 50\% do peso do fruto correspondem ao bagaço e à casca, o que gera um impasse na disposição destes subprodutos no meio ambiente. A casca desta fruta cítrica possui celulose, hemicelulose, lignina e altas concentrações de pectina (aproximadamente 42,5\%), sendo este subproduto um potencial adsorvente (Feng et al., 2011; Miller et al., 2013;).

Outro material precursor de adsorventes é o lodo ativado oriundo de indústrias frigoríficas, uma vez que este é rico em carbono. As regiões que possuem sua economia baseada na atividade frigorífica, como na região oeste de Santa Catarina, ocasionam uma elevada produção de lodo ativado, devido às características do tratamento dos efluentes oriundos destes processos, sendo gerados até $20 \mathrm{~g}$ de lodo por litro de água consumida (CHÁVEZ et al., 2005). De acordo com Zanotto et al. (2011), em 2004 foram produzidos 8,2 milhões de toneladas de carne de frango no Brasil, sendo que o requerimento de água para o abate e processamento de um frango aproxima-se de 30 litros, estimando-se a geração de aproximadamente 149 milhões de toneladas de efluentes por ano, ocasionando-se uma elevada produção de lodo.

Dessa forma, este estudo fundamenta-se em utilizar a casca da laranja e o lodo de frigoríficos como matérias primas para a produção de carvão ativado, tendo como objetivo a adsorção de corantes em corpos d'água, bem como uma finalidade para o reaproveitamento de resíduos de processos industriais, tornando viável o emprego deste tipo de remoção de poluentes por empregar precursores de baixo custo.

\section{MATERIAS E MÉTODOS}

\subsection{Preparo da Matéria-Prima}

Os materiais precursores, casca de laranja e lodo ativado de frigorífico, foram lavados com água para remoção de sujidades, sendo dispostos em estufa à temperatura superior a 100 ${ }^{\circ} \mathrm{C}$ por $24 \mathrm{~h}$ no caso da casca de laranja e por $48 \mathrm{~h}$ para o lodo ativado, para remoção da umidade, sendo posteriormente estes materiais moídos para posterior ativação.

\subsection{Ativação}

Ativaram-se as amostras com ácido fosfórico $\left(\mathrm{H}_{3} \mathrm{PO}_{4}\right)$ 85\% e água ultra pura, totalizando uma solução de $150 \mathrm{ml}$.

Para ambos os carvões conduziu-se o processo de ativação à $80^{\circ} \mathrm{C}$ e $120 \mathrm{rpm}$, alterandose nesta etapa o tempo de ativação, às razões $\mathrm{H}_{3} \mathrm{PO}_{4}: \mathrm{H}_{2} \mathrm{O}$ e a temperatura de ativação, conforme demonstrado na Tabela 1 . As amostras foram mantidas em estufa por 24 horas à temperatura de $90^{\circ} \mathrm{C}$ após ativação.

\subsection{Carbonização}

Carbonizaram-se as amostras por duas horas em mufla à atmosfera ambiente, sendo estas armazenadas em um dissecador após este processo. Lavou-se o material com uma solução de 
bicarbonato de sódio $1 \%$ até a estabilização do $\mathrm{pH}$ dos adsorventes. Para remoção da umidade levaram-se as amostras a uma estufa à temperatura de $110^{\circ} \mathrm{C}$ pelo tempo de 24 horas.

Tabela 1 - Combinações de variáveis para experimento carvão ativado de casca de laranja.

\begin{tabular}{|c|c|c|c|}
\hline Ensaio & Temperatura de Carbonização $\left({ }^{\circ} \mathrm{C}\right)$ & Temperatura de Ativação $\left({ }^{\circ} \mathrm{C}\right)$ & $\mathrm{H}_{3} \mathrm{PO}_{4}: \mathrm{H}_{2} \mathrm{O}$ \\
\hline 1 & 600 & 80 & $1: 1$ \\
\hline 2 & 400 & 80 & $1: 1$ \\
\hline
\end{tabular}

\subsection{Isoterma de Adsorsão}

As análises de equilíbrio foram conduzidas em erlenmeyers, cada um com massas de carvão variando de $0,1 \mathrm{~g}$ a $1 \mathrm{~g}$, com variação de $0,1 \mathrm{~g}$ a cada erlenmeyer. Junto a essa massa de carvão, foram adicionados $100 \mathrm{~mL}$ de solução de azul de metileno com concentração de 100 mg. $\mathrm{L}^{-1}$ para a casca de laranja e $70 \mathrm{mg} . \mathrm{L}^{-1}$ para o lodo ativado. Ajustou-se o $\mathrm{pH}$ em torno de 7,0 , empregando-se uma solução de $\mathrm{NaOH}(0,01 \mathrm{M})$. Agitou-se a solução a $120 \mathrm{rpm}$ em shaker por 24 horas. Decorrido o tempo necessário, as leituras foram feitas com o auxílio de um espectrofotômetro no comprimento de onda característico de $665 \mathrm{~nm}$.

\subsection{Cinética de Adsorsão}

As avaliações das cinéticas de degradação do corante foram realizadas pela aplicação de um grama de carvão em $500 \mathrm{~mL}$ de solução com concentração do corante em $100 \mathrm{mg} . \mathrm{L}^{-1}$ para o carvão da casca de laranja e $70 \mathrm{mg} . \mathrm{L}^{-1}$ para o do lodo ativado. O sistema foi mantido sob agitação constante e à temperatura de $20^{\circ} \mathrm{C}$, através de um banho termostático, simulando a temperatura média de um efluente industrial. Alíquotas foram retidas durante a execução dos experimentos cinéticos, sendo centrifugadas para remoção de particulados durante 10 minutos com uma rotação de $3600 \mathrm{rpm}$. A concentração de corante foi determinada através da espectrofotometria com comprimento de onda característico de $665 \mathrm{~nm}$.

\section{RESULTADOS E DISCUSSÃO}

\subsection{Cinética de Adsorsão}

As cinéticas de adsorção foram desenvolvidas no intuito de compreender o mecanismo que rege este processo, sendo os resultados ajustados pelos modelos de cinética de pseudoprimeira ordem, pseudossegunda ordem e difusão intrapartícula. A avaliação quantitativa dos modelos foi realizada pela comparação dos coeficientes de determinação $\left(\mathrm{R}^{2}\right)$ e pelos valores de $\mathrm{q}_{\mathrm{e}}$ calculados $-\mathrm{q}_{\mathrm{e}}$ (calc.) - versus os resultados de $\mathrm{q}_{\mathrm{e}}$ obtidos experimentalmente $-\mathrm{q}_{\mathrm{e}}$ (exp.).

Através da linearização dos resultados para os modelos de pseudo-primeira ordem e pseudossegunda ordem, o modelo de pseudossegunda ordem, apresentou um melhor ajuste, sendo demonstrado nas Figuras 1 e 2 para os carvões obtidos a partir do lodo ativado e casca de laranja, respectivamente. 
(a)

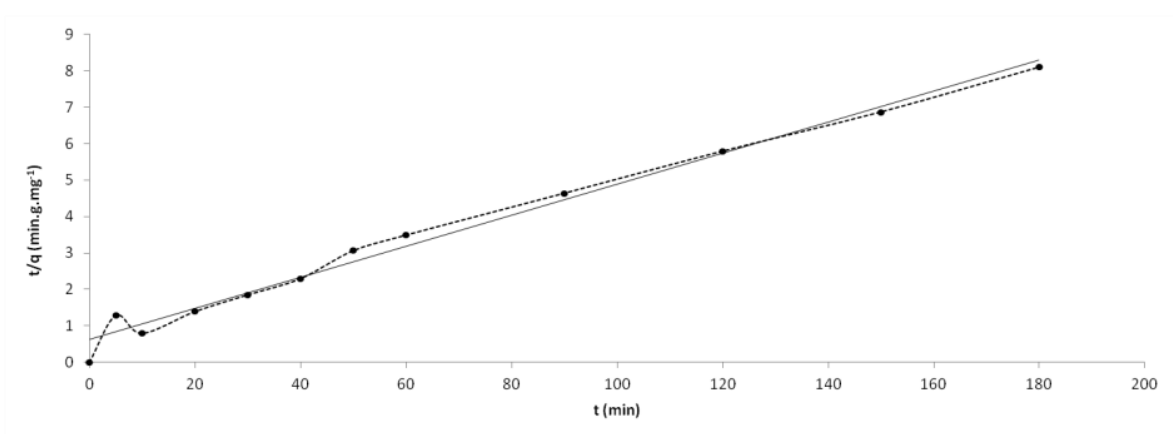

(b)

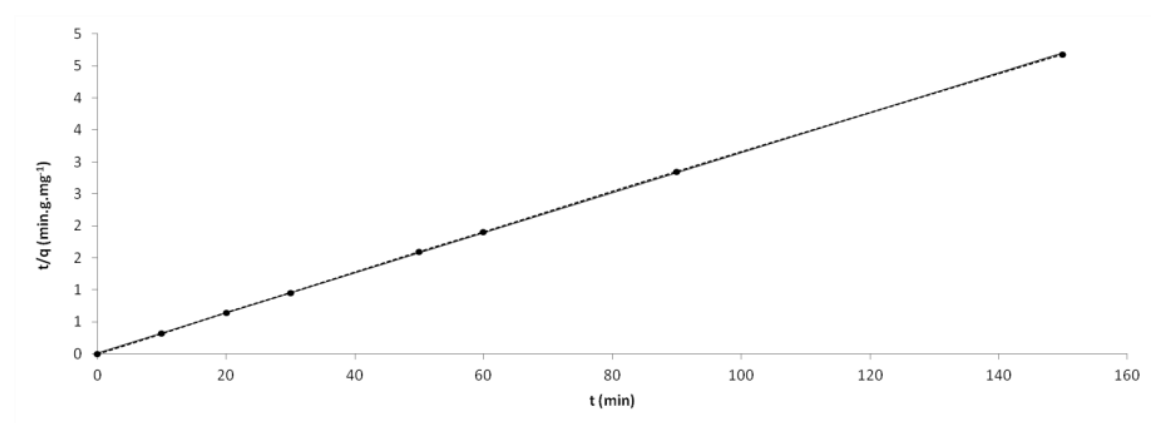

Figura 1 - Linearização dos parâmetros para o modelo de pseudossegunda ordem para carvão de lodo ativado em (a) $400{ }^{\circ} \mathrm{C}$ e (b) $600{ }^{\circ} \mathrm{C}$.

(a)

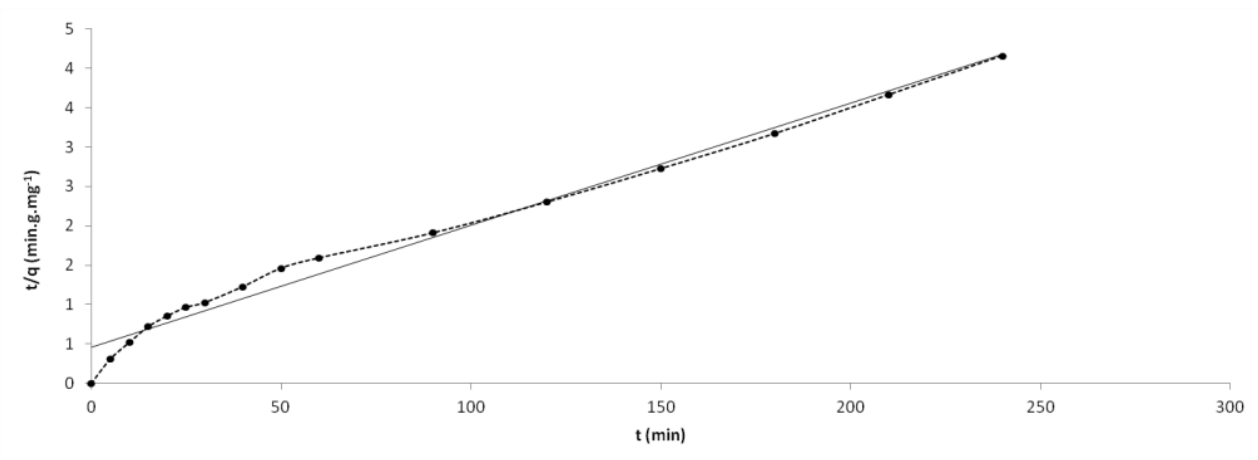

(b) 


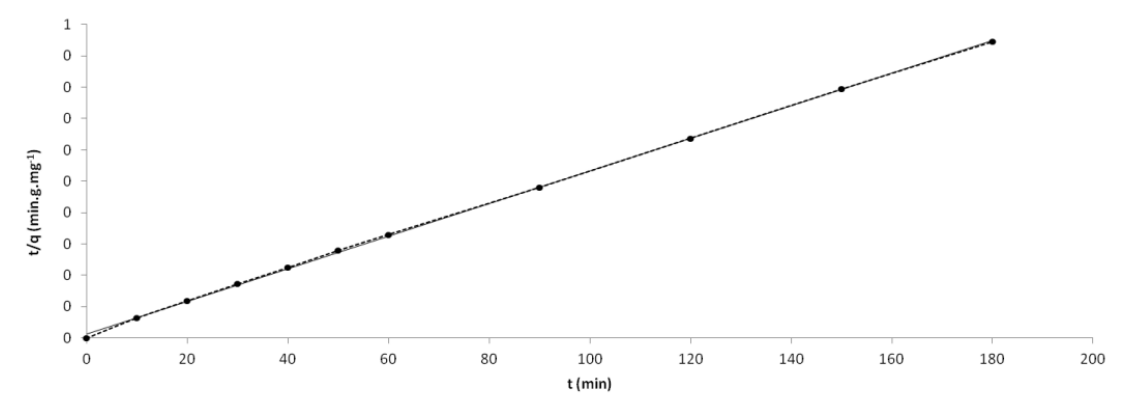

Figura 2 - Linearização dos parâmetros para o modelo de pseudossegunda ordem para carvão de casca de laranja em (a) $400{ }^{\circ} \mathrm{C}$ e (b) $600{ }^{\circ} \mathrm{C}$.

Com base na definição do comportamento da adsorção determinaram-se a taxa de adsorção no equilíbrio qe $\left(\mathrm{mg}_{\mathrm{g}} \mathrm{g}^{-1}\right)$ e as constantes de velocidade $\mathrm{k}_{2}$ com carvões carbonizados, conforme apresentado na Tabela 2.

Tabela 2 - Parâmetros cinéticos de pseudossegunda ordem

\begin{tabular}{|c|c|c|c|c|c|}
\hline Amostra & $\begin{array}{c}\text { qe (exp.) } \\
\text { mg.g }^{-1}\end{array}$ & $\begin{array}{c}\text { qe (calc.) } \\
\text { mg.g }^{-1}\end{array}$ & Desvio (\%) & $\begin{array}{c}\mathbf{k}_{\mathbf{2}}(\mathbf{g . m g} \\
\left.\mathbf{1 . m i n}^{-1}\right)\end{array}$ & $\mathbf{R}^{\mathbf{2}}$ \\
\hline $\begin{array}{c}\text { Casca de } \\
\text { Laranja }-400{ }^{\circ} \mathrm{C}\end{array}$ & 57,69 & 64,52 & 10,58 & 0,00053 & 0,9806 \\
\hline $\begin{array}{c}\text { Casca de } \\
\text { Laranja - 600 }{ }^{\circ} \mathrm{C}\end{array}$ & 37,79 & 38,46 & 1,74 & 0,00101 & 0,9997 \\
\hline $\begin{array}{c}\text { Lodo Ativado } \\
400^{\circ} \mathrm{C}\end{array}$ & 22,22 & 23,81 & 6,68 & 0,00285 & 0,9867 \\
\hline $\begin{array}{c}\text { Lodo Ativado } \\
600^{\circ} \mathrm{C}\end{array}$ & 32,01 & 31,95 & 0,19 & 0,05184 & 0,9999 \\
\hline
\end{tabular}

A análise dos resultados leva a definição de que os carvões obtidos a $600{ }^{\circ} \mathrm{C}$ apresentaram os melhores resultados tanto relativos ao $\mathrm{R}^{2}$ quanto às constantes cinéticas, o que possivelmente deve-se ao fato de que em maiores temperaturas a degradação da estrutura carbonácea é maior, gerando um maior volume de poros, o que aumenta a área superficial para remoção de corantes.

A eficiência de remoção do corante catiônico carbonizado pelos carvões ativados a 600 ${ }^{\circ} \mathrm{C}$ atingiu $98 \%$ para o carvão da casca de e $77 \%$ para o lodo ativado.

\subsection{Isoterma de Adsorção}

O equilíbrio de adsorção do corante azul de metileno foi expresso em termos de isotermas de adsorção, sendo utilizados os modelos de Langmuir e Freundlich. Foram analisados as constantes e seus respectivos coeficientes de determinação, conforme Tabela 3, demonstrando que a isoterma de Freundlich foi o modelo que melhor ajustou-se aos dados experimentais, ou seja, a adsorção deste composto ocorre por adsorção multicamada em superfície heterogênea, que é comprovado pelas Figuras 5, 6, 7 e 8. 
Tabela 3 - Parâmetros das isotermas de Freundlich

\begin{tabular}{|c|c|c|c|c|}
\hline \multicolumn{5}{|c|}{ Freundlich } \\
\hline Matéria-prima & K $\left._{\mathbf{f}}\left(\mathbf{m g . g}^{\mathbf{- 1}}\right) .\left(\mathbf{l . m g}^{\mathbf{- 1}}\right)^{\mathbf{1 / n}}\right)$ & $\mathbf{1 . n}^{\mathbf{- 1}}$ & $\mathbf{n}$ & $\mathbf{R}^{\mathbf{2}}$ \\
\hline Casca de Laranja & 92,37 & 0,381 & 2,624 & 0,8362 \\
\hline Lodo de Frigorífico & 24,680 & 0,192 & 5,214 & 0,7151 \\
\hline
\end{tabular}

A análise dos dados demonstra que a isoterma de Freundlich é favorável, uma vez que o valor de n para ambas as amostras está entre 1 e 10.

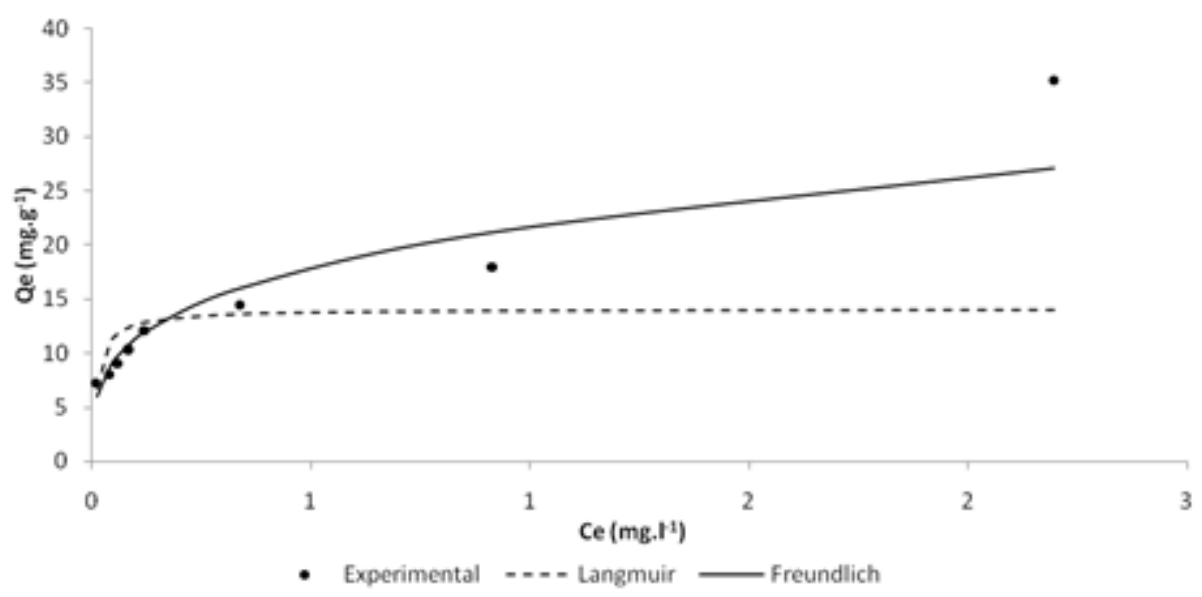

Figura 5 - Isoterma de adsorção para o carvão ativado de lodo de frigorífico carbonizado a $400{ }^{\circ} \mathrm{C}$ por 2 horas.

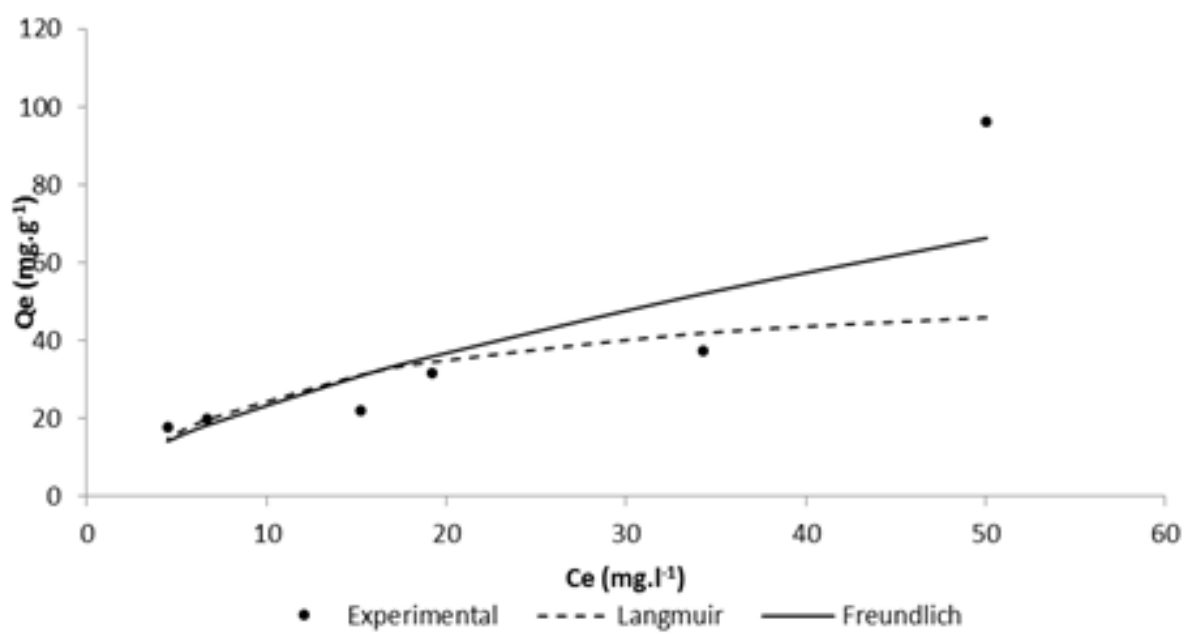

Figura 6 - Isoterma de adsorção para o carvão ativado de casca de laranja carbonizado a $400{ }^{\circ} \mathrm{C}$ por 2 horas. 


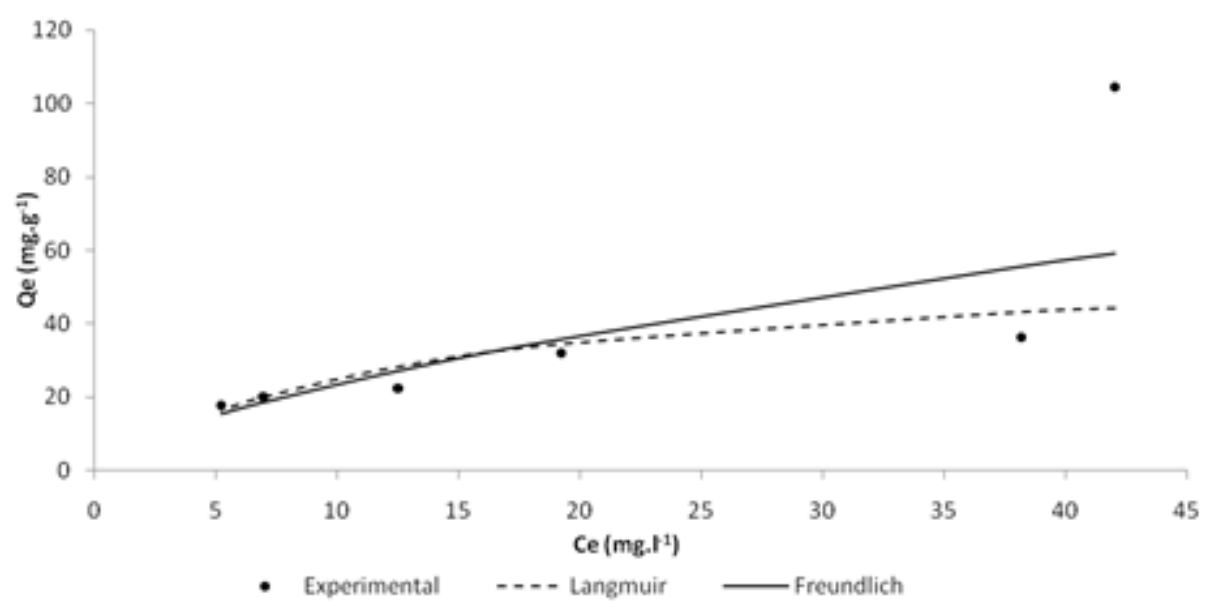

Figura 7 - Isoterma de adsorção para o carvão ativado de lodo de frigorífico carbonizado a $600{ }^{\circ} \mathrm{C}$ por 2 horas.

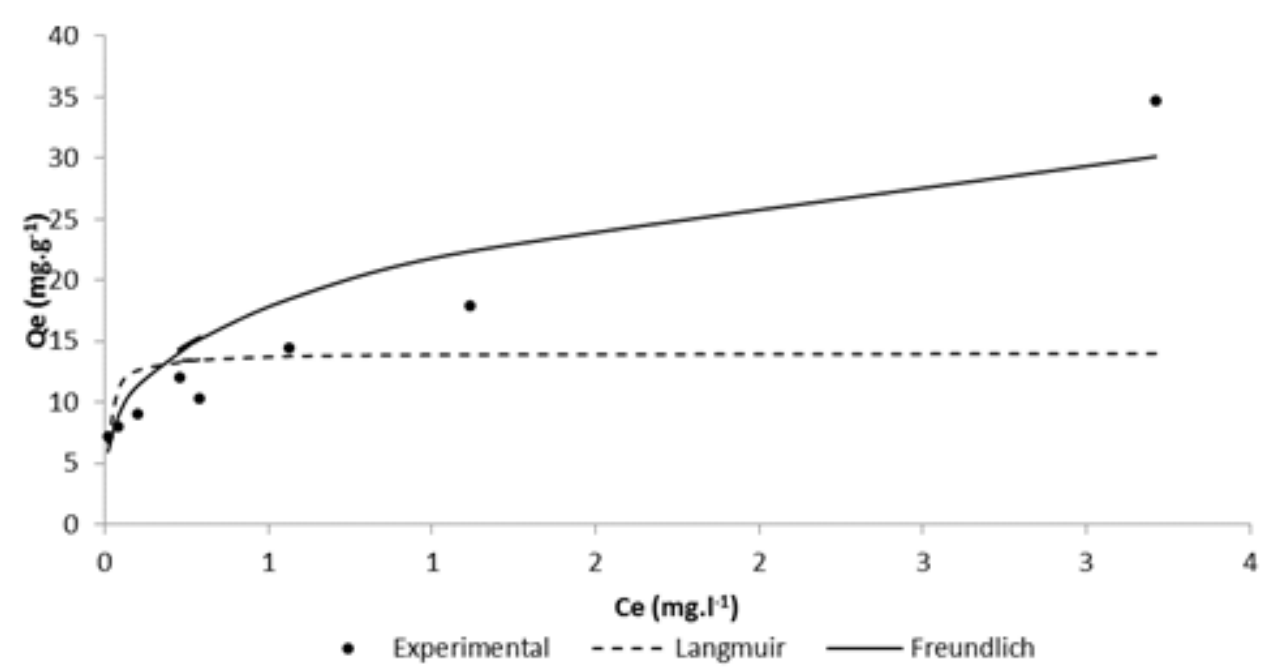

Figura 8 - Isoterma de adsorção para o carvão ativado de casca de laranja a $600{ }^{\circ} \mathrm{C}$ por 2 horas.

\section{CONCLUSÕES}

Após a realização deste estudo pode-se observar que o desempenho na adsorção do corante azul de metileno foi melhor com o carvão obtido a partir da casca de laranja, quando comparado com o carvão obtido a partir do lodo frigorífico.

Em ambos os carvões os dados ajustaram-se melhor ao modelo de pseudossegunda ordem e a isoterma de Freundlich, onde esta foi utilizada para descrever o equilíbrio termodinâmico, e os valores de $\mathrm{n}$ foram 2,624 para o casca de laranja e 5,214 para o lodo, demonstrando que a 
isoterma é favorável, e $\mathrm{K}_{\mathrm{F}}=92,37\left(\left(\mathrm{mg} \cdot \mathrm{g}^{-1}\right) \cdot\left({\mathrm{L} \cdot \mathrm{mg}^{-1}}^{1 / \mathrm{n}}\right)\right.$ e 24,68 $\left(\left(\mathrm{mg} \cdot \mathrm{g}^{-1}\right) \cdot\left(\mathrm{L}_{\mathrm{mg}} \mathrm{mg}^{-1}\right)^{1 / \mathrm{n}}\right)$, para a casca de laranja e lodo, respectivamente.

A remoção de corante com melhor eficiência para o carvão da casca de laranja atingiu $98 \%$ a $400{ }^{\circ} \mathrm{C}$ enquanto que para o lodo ativado mostrou-se a $600{ }^{\circ} \mathrm{C}$ com $77 \%$.

Com base nas eficiências de adsorção obtidas, confirma-se que a utilização de resíduos industriais destas naturezas distintas apresentam satisfatórias capacidades de remoção do corante azul de metileno.

\section{REFERÊNCIAS BIBLIOGRÁFICAS}

CHÁVEZ, C. P.; CASTILlO, R. L.; DENDOOVEN, L.; SILVA, E. M. E. Poultry Slaughter Wastewater Treatment With an Up-flow Anaerobic Sludge Blanket (UASB) Reactor. Bioresource Technology, v. 96, pg. 1730-1736, 2005.

FENG, N.; GUO, X.; LIANG, S.; ZHU, Y.; LIU, J. Biosorption of Heavy Metals from Aqueous Solutions by Chemically Modified Orange Peel. Journal of Hazardous Materials, v. 185, pg. 49-54, 2011.

INSTITUTO BRASILEIRO DE GEOGRAFIA E ESTATÍSTICA. Produção Agrícola Municipal - Culturas Temporárias e Permanentes 2011. São Paulo, 2012. 98 p.

MEZOHEGYI, G.; VAN DER ZEE, F. P.; FONT, J.; FORTUNY, A.; FABREGAT, A. Towards Advanced Aqueous Dye Removal Processes: A Short Review on the Versatile Role of Activated Carbon. Journal of Environmental Management, v. 102, p. 148-164, 2012.

MILLER, F.; CALDEIRÃO, L.; DORTA, C.; MARINELLI, P. S. Obtenção de Acçúcares Fermentescíveis a partir da Casca de Laranja e Bagaço de Cana-de-Açúcar. Revista Analytica, v. 64, pg. 2, 2013.

SILVA, A. S. (2005). Avaliação da Capacidade de Remoção de Saxitoxinas por Diferentes Tipos de Carvão Ativado em Pó (CAP) Produzidos no Brasil. Dissertação de Mestrado em Tecnologia Ambiental e Recursos Hídricos, Publicação PTARH.DM-083/05, Departamento de Engenharia Civil e Ambiental, Universidade de Brasília, Brasília, DF, 115p.

WANG, L. Application of Activated Carbon Derived From 'Waste' Bamboo Culms for the Adsorption of Azo Disperse Dye: Kinetic, Equilibrium and Thermodynamic Studies. Journal of Environmental Management, v. 102, 79-87, 2012.

YANAN, D.; YANLEI, S.; WENJUAN, C.; JINMING, P.; YAN, Z.; ZHONGYI, J. Ultrafiltration Enhanced with Activated Carbon Adsorption for Efficient Dye Removal from Aqueous Solution. Chinese Journal of Chemical Engineering, v. 19, pg. 863-869, 2011.

ZANOTTO, D. L. Flotado de Efluentes de Frigoríficos de Suínos e Aves. Avicultura. Dez. 2011. <http://pt.engormix.com/MA-avicultura/administracao/artigos/flotado-efluentes-frigorif ico-suinos-t834/124-p0.htm>. Data de acesso: 20 de abril de 2014. 